\title{
Fractography Study of Explanted Intramedullary Nails
}

IOAN CRISTESCU ${ }^{1}$, IULIAN ANTONIAC ${ }^{2}$, MIHAI BRANZEI ${ }^{2 *}$, BRANDUSA GHIBAN ${ }^{2}$, ROBERT CIOCOIU ${ }^{2}$, ION CIUCĂ ${ }^{2}$, AUGUSTIN SEMENESCU ${ }^{2}$, SEBASTIAN GRADINARU ${ }^{3 *}$, DANIEL POP ${ }^{2}$, ANCA DANIELA RAICIU ${ }^{4}$

${ }^{1}$ Clinical Emergency Hospital Bucharest, Department Orthoped \& Traumatol, 8 Floreasca Av., 014461 Bucharest, Romania

${ }^{2}$ University Politehnica of Bucharest, 313 Splaiul Independentei Str., 060042, Bucharest, Romania

${ }^{3}$ Carol Davila University of Medicine and Farmacy, 37 Dionisie Lupu Str., 030167, Bucharest, Romania

${ }^{4}$ Titu Maiorescu University, Faculty Pharmacy, Dept. Pharmacognosy Phytochem Phytoterapy, 16 Gh. Sincai Str., Bucharest, Romania

This study comprises the studies performed on six in vivo failed centromedullary fixation devices, three made of stainless steel $316 \mathrm{~L}$ and three of titanium alloy Ti-6Al-4V. Fractographic studies were performed using stereomicroscopy and scanning electron microscopy while metallographic studies were performed by light microscopy. Loading mode which caused failure was inferred based upon surface fracture topography and light microscopy studies were performed to observe if abnormal microstructures or inclusions could be the cause of the failure. In all cases the chemical composition was according to standard specifications and the microstructures appeared normal with low inclusionary content. The mode of failure was found to be fatigue and the crack initiation site was on the implant surface on roughness features and surface induced defects.

Keywords: stainless steel, Ti-6Al-4V, intramedullary fixation device, fatigue, failure

Fracture surface study was performed throughout the history first by naked eye and starting from the XIX ${ }^{\text {th }}$ century high magnifications were achieved by optical microscopy and later even higher magnifications were possible using the scanning and transmission electron microscopes [1].

Fractography is regarded as the study of fracture surfaces of materials. Smiths' [2] view on fractography is that it is an art of interpretation of fracture mechanisms in a specimen by fracture surface examination. Its major use is to determine the cause of failure in structures and development and evaluation of crack initiation and growth.

This attempt to relate the topography of the fractured surface to the cause and mechanisms of proves extremely useful in failure analysis and forensic engineering.

The goal of every implant is to restore anatomical configuration to ensure the achievement of maximal functionality when healing is complete. To reach this goal the implant plays the most important role and its success depends on numerous factors: material and processing factors [3,4], design factors [5, 6] or external factors such as placement [7], placement technique [8-10], patient cooperation [11-12] and sometimes even fracture healing can alter the performance [14, 15].

This study is directed towards most stressed implants - the implants used in orthopedics from which the interlocking nail type was chosen given loading conditions that can concentrate stresses at proximal and distal ends.

The use of intramedullary interlocking nails has low impact by minimizing tissue damage from a surgical point of view and offers a good and stable fracture fixation from a mechanical perspective. This method is successfully used for fracture treatment of long bones, the tibia and femur, and it offers better biomechanical results when compared to fixed-angled plates [16].

Given the loads in the system implant failure can occur by overload (an unlikely failure scenario) or most common by fatigue.

Fatigue can be regarded as a process of localized and permanent change in the structure of a material subjected to stresses and strains that fluctuate. At sufficient number of fluctuations cracks can appear and it may culminate with complete fracture.

Metal fatigue has been extensively studied, the fatigue strength in air of Ti-6Al-4V being reported at 610-625MPa [17] and that of austenitic stainless steel $316 \mathrm{~L}$ at $220 \mathrm{MPa}$ as cast and approximately $390 \mathrm{MPa}$ as forged [18]. Obviously, post processing enhances the fatigue strength by creating compressive surface stresses.

Fatigue of materials when inserted in the human body is greatly accelerated by the harsh environment surrounding the implant [19].

Given these harsh conditions: stresses, fatigue and corrosion failure of the implant becomes plausible. To indentify the cause of failure can mitigate the number of failed devices by adopting appropriate procedures for material processing, placement position and technique as well as recommending movement restrictions to the patient. 
The fractographic examination is the main tool to obtain this vital information.

\section{Experimental part}

Materials and methods

In this study the failure analysis of six failed metallic implants gathered over several years is presented. The six in vivo failed implants were retrieved according to hospital settled protocol, disinfected, marked and photographed for traceability, sealed and transferred to be studied.

The received specimens were cut using a metallographic cutting machine to obtain the regions of interest (the fracture surfaces) and metallographic samples for light microscopy studies. The fracture surfaces were studied by naked eye and using a stereomicroscope Olympus SZX7, then using scanning electron microscopes ESEM Philips XL 30 TMP and FEI Quanta Inspect F, both equipped with energy dispersive X-ray spectrometers (EDS).

The chemical composition of the implant was studied in respect to main alloying elements by EDS. Metallographic specimen preparation was performed according to the studied alloy and light microscopy studies were performed using the Reichert UnivaR and Olympus BX51 microscopes.

All results were used to infer failure mode and cause.

\section{Results and discussions}

In following paragraphs the six case studies on explanted failed intramedullary nails are presented. Three implants are made of stainless steel 316L and the other of Ti-6Al-4V alloy, a reason to divide the study in two parts: first part groups the stainless steel and the second the Ti-6Al-4V implants.

\section{Stainless steel nails}

Case 1: Seidel centro - medullar nail

A centro-medullar nail was extracted from a patient after failure according to hospital settled protocol. The catastrophic failure occurred at the middle of the length of the implant, as depicted by Fig. 1.

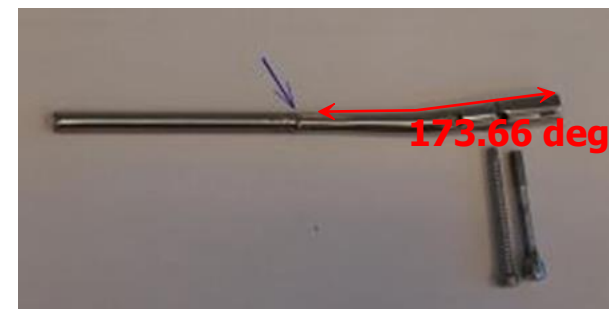

Fig. 1. Failed Seidel centro-medullar nail explant. Arrow points to failure.

The major alloying elements were determined by EDS, their concentration is shown in table 1.

Table 1

MAIN ALLOYING ELEMENTS CONCENTRATION

\begin{tabular}{|l|l|l|l|l|l|}
\hline Element & $\mathrm{Mo}$ & $\mathrm{Cr}$ & $\mathrm{Mn}$ & $\mathrm{Ni}$ & $\mathrm{Fe}+$ others \\
\hline \%wt. & 2.26 & 18.34 & 3.03 & 13.56 & Bal. \\
\hline
\end{tabular}

According to the composition from table 1 the alloy is a 316L stainless steel and it conforms to ASTM F 138 and ISO 5832-1 specifications for chemical composition. Metallographic specimens were obtained from an intact region of the implant and prepared using the standard procedure for stainless steel in order to study their microstructure. 


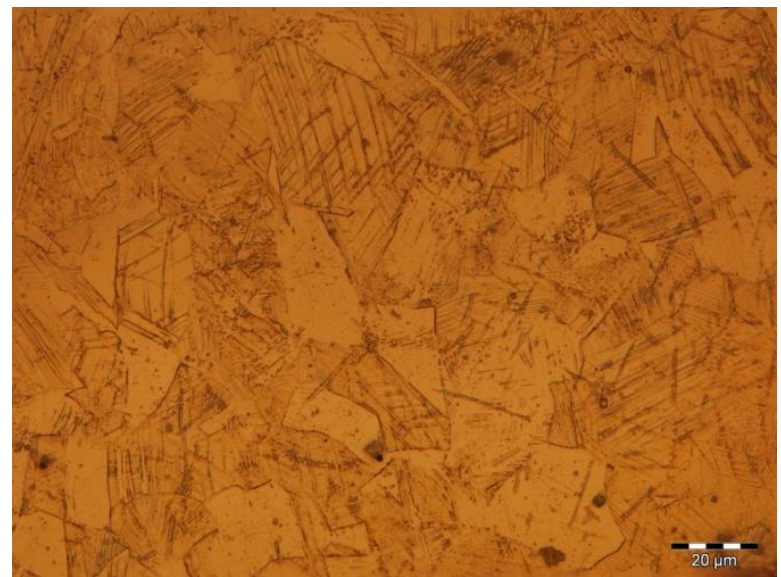

Fig. 2.Optical micrographs showing stainless steel microstructure

The micrograph shown in Fig. 2 shows a typical solid solution with twins suggesting a FCC system, the austenite. The inclusion content determined prior etching established that the steel is clean (low inclusions content) this way a possible cause of failure can be eliminated.

Further investigations employed a macroscopic study of the fracture surface using the stereomicroscope. The images shown in Fig. 3 reveal general fracture type aspects.

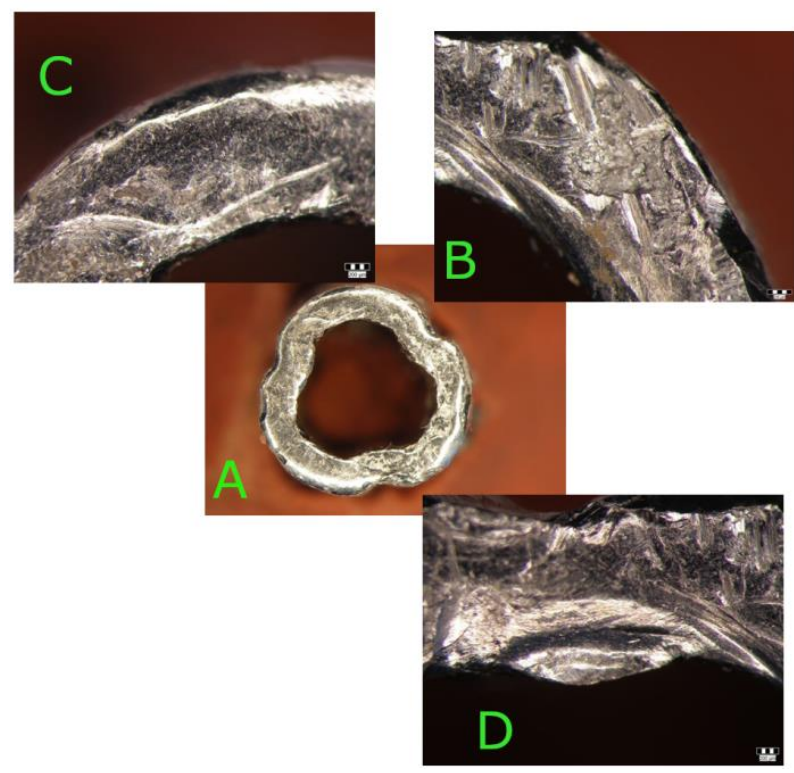

Fig. 3. Images obtained using the stereomicroscope showing fracture surface

In fig. 3.a the general view of the fracture surface is presented, the section shows no deformations, thus no overload can be assumed. Fatigue failure was the failure mechanism culprit, fatigue striations can be seen in fig. 3.b to 3.d, most obvious in the last. Galling is present in fig 3.b, a form of wear between sliding surfaces. Crack growth separated the surfaces and under compressive load some material was pulled with the contacting surface.

In Fig. 3.d a region which resembled to a brittle failure was inferred at this the low magnification. In this area final fracture occurred; the section area was small enough and unable to withstand the applied load.

Using the scanning electron microscope key fracture aspects were studied in an attempt to find crack origin and infer its growth direction. 


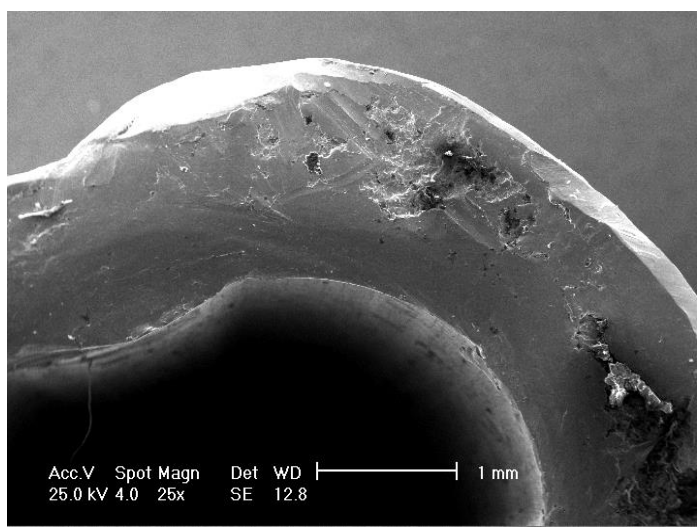

a.

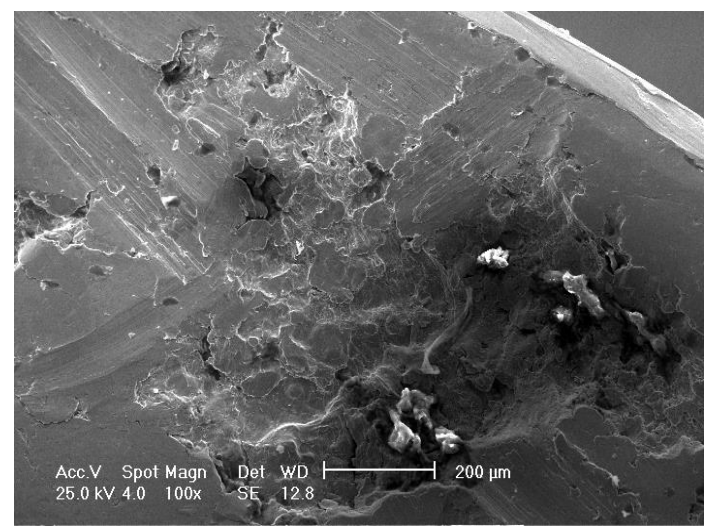

b.

Fig. 4. Scanning electron micrographs showing fracture surface a. general aspects and $b$. a detail which resembles to tire marks

Fig. 4.a shows a smooth surface typical for crack growth during fatigue and a region with various morphologies where final failure occurred. Higher magnifications used (Fig. 4.b) revealed tool damage caused by the physician in his attempt of implant removal; these marks run on NV-SE and NE-SV directions starting from the edge of the implant.

Unfortunately these marks destroyed most of the features useful for crack origin and growth direction inference.

Deeper insights of the fracture region shown in Fig. 5.a and b revealed some details regarding crack growth and failure mode.

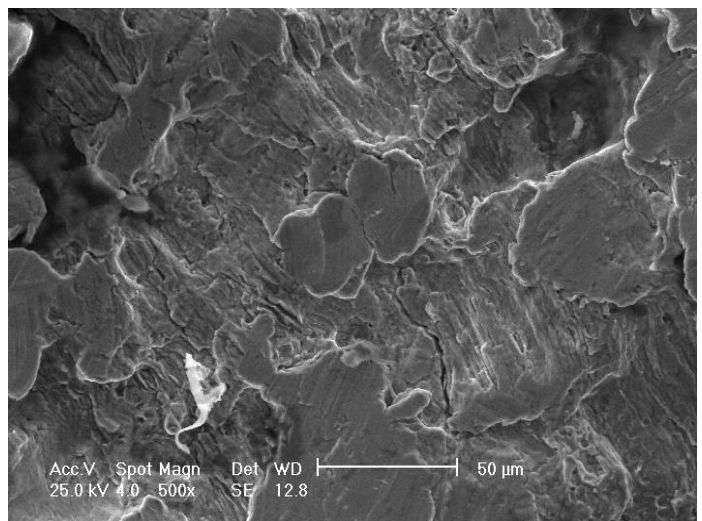

a.

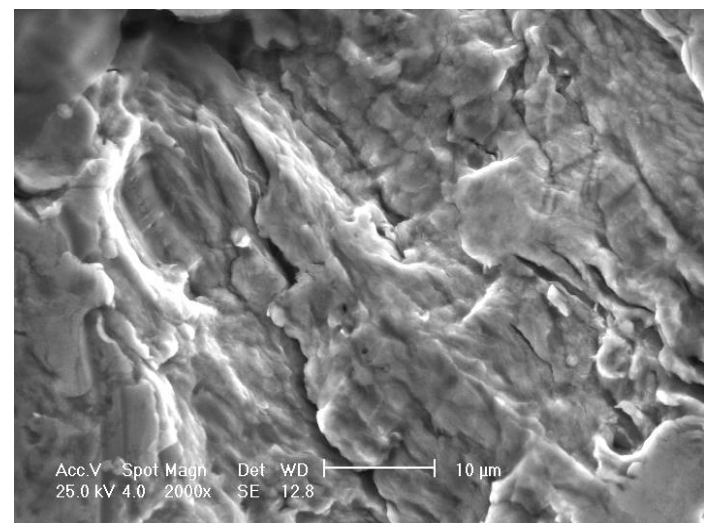

b.

Fig. 5. Scanning electron micrographs showing fracture in a. galling and cleavage fracture and b. cleavage facets and micro-cracks

Fig. 5.a reveals a NV-SE failure direction with galling caused by NE-VS sliding direction. Microscopic cracks are oriented on the same NV-SE direction and in Fig. 5.b, at higher magnifications, crack branching can be observed. The cracks extend on different planes.

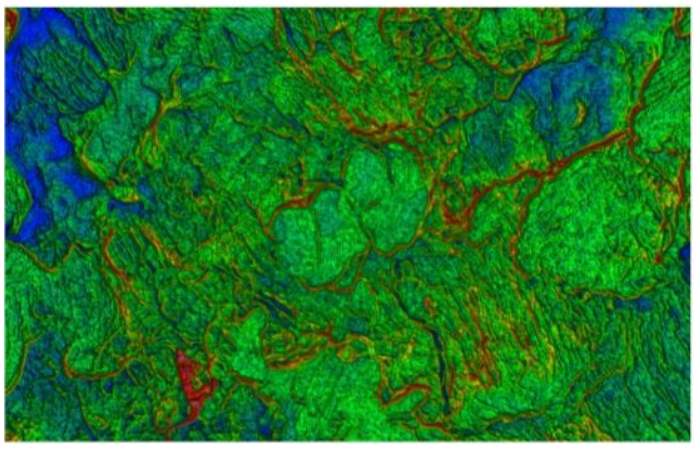

a.

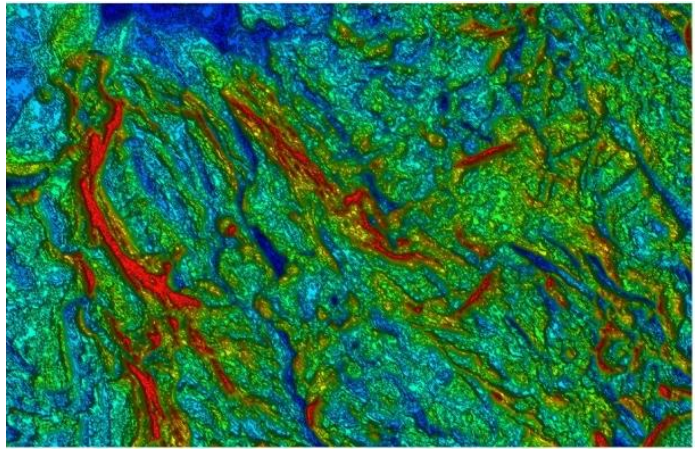

b.

Fig. 6. Artificial height coloring of regions of interest from fig. 5.a and 5.b

Fig. 6 is constructed by an artificial height coloring [20] of the topographic secondary electron scanning electron micrograph. The failure origin can be inferred in the NV region, near implant surface, while main loading mode is assumed to be fatigue in torsion. 
Case study 2: tibial interlocking Kuntscher nail

The second failed implant presented in this study shows a similar failure mode as the first, in the middle of the length of the centro-medullar nail. The explant is shown in fig. 7, immediately after extraction and disinfection.

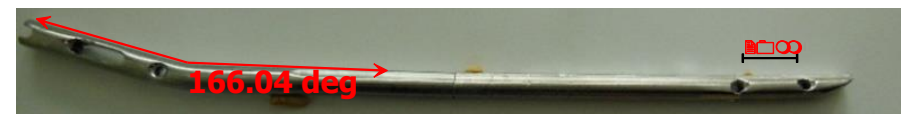

Fig. 7. Failed implant. Failure can be observed in the middle of the length.

Using EDS the concentration of the major alloying elements was determined and it is presented in table 2.

Table 2

MAJOR ALLOYING ELEMENT CONCENTRATION

\begin{tabular}{|l|l|l|l|l|}
\hline Element & Mo & $\mathrm{Cr}$ & $\mathrm{Ni}$ & $\mathrm{Fe}+$ others \\
\hline \%wt. & 3.21 & 16.81 & 13.01 & Bal. \\
\hline
\end{tabular}

According to this composition a 316L stainless steel is the implant material with alloying element conforming to ASTM F 138 and ISO 5832-1 range. From a sound region of the implant metallographic specimens were obtained and prepared accordingly to study the microstructure.

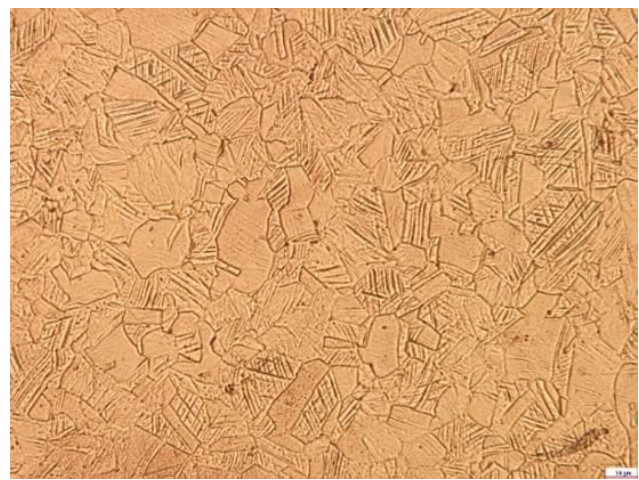

Fig. 8. Optical micrograph showing an austenitic microstructure.

The microstructure shown in Fig. 8 reveals a typical austenitic structure with fine grains and low inclusion content. Regarding the microstructure and inclusion content the steel conforms to specifications for its use.

Fracture surface was first observed using the stereomicroscope; details from this investigation are shown in fig. 9.

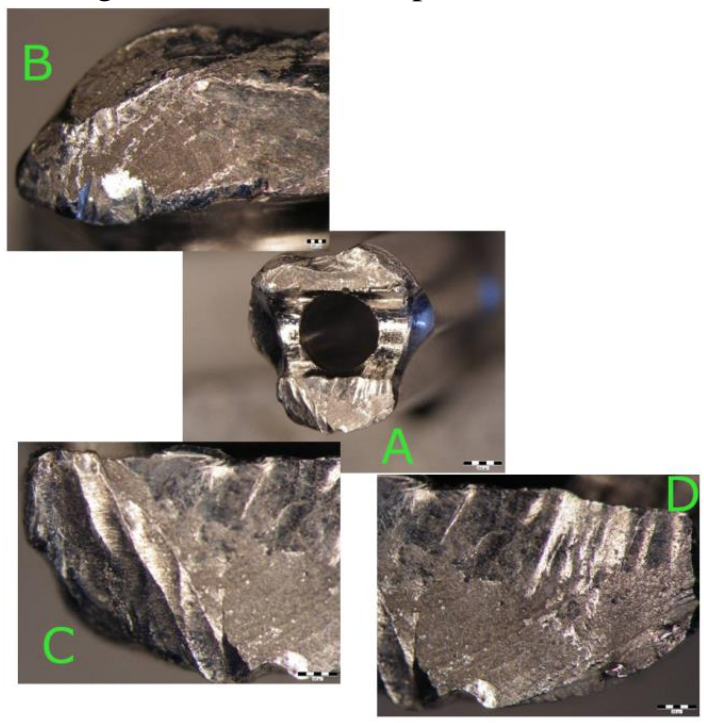

Fig. 9. Fracture surface observed with the stereomicroscope 
The fracture aspects depicted in Fig. 9.a suggest a failure in bending, the striations and smooth surface followed by a different fracture morphology observed in Fig. $9 \mathrm{~b}$ through $\mathrm{d}$ are typical signs of fatigue. The implant failed by fatigue in a bending loading scenario.

By SEM crack origin and directions were easily located in this case.

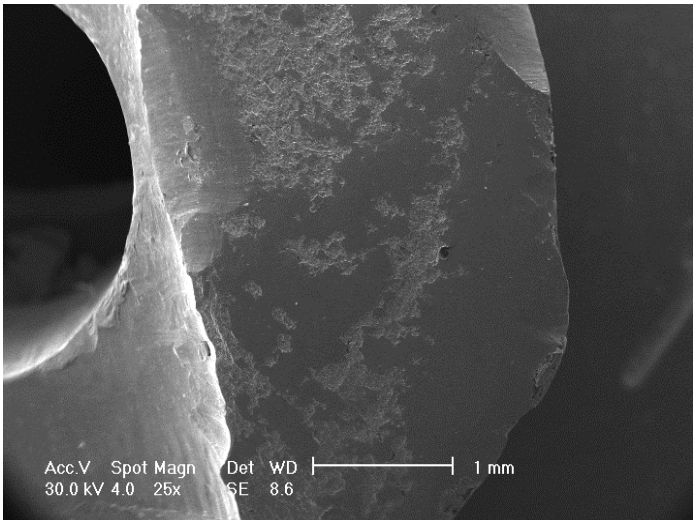

a.

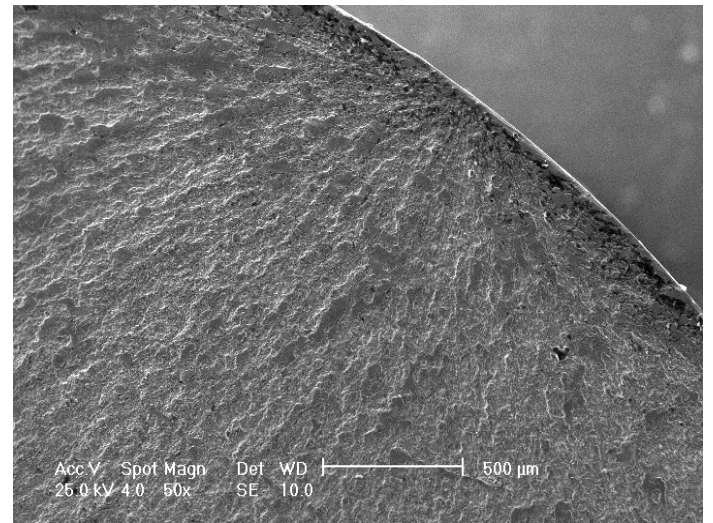

b.

Fig. 10. Fracture surface observed by SEM using secondary electron detector showing a. galling and b. crack growth diverging from crack origin

In Fig. 10.a it can be seen how the fracture suddenly changes planes in its growth. Also signs of galling are visible near the exterior edge of the implant. Again a smooth surface occupies a large amount which typical for crack growth by fatigue followed by a small region with crystalline morphology where catastrophic failure occurred [21].

In fig. 10.b the crack origin can be easily located by tracing backwards the branched river-lines towards the outside edge of the implant. Aspects of galling can be observed, by compression loading the fractured surfaces were in sliding contact.

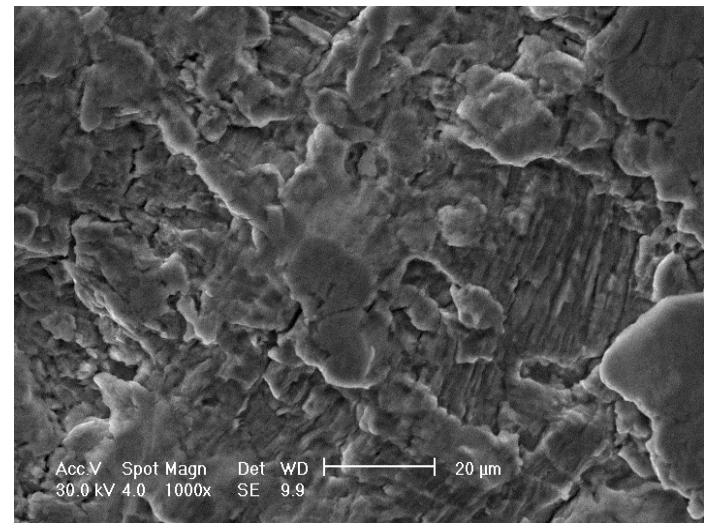

a.

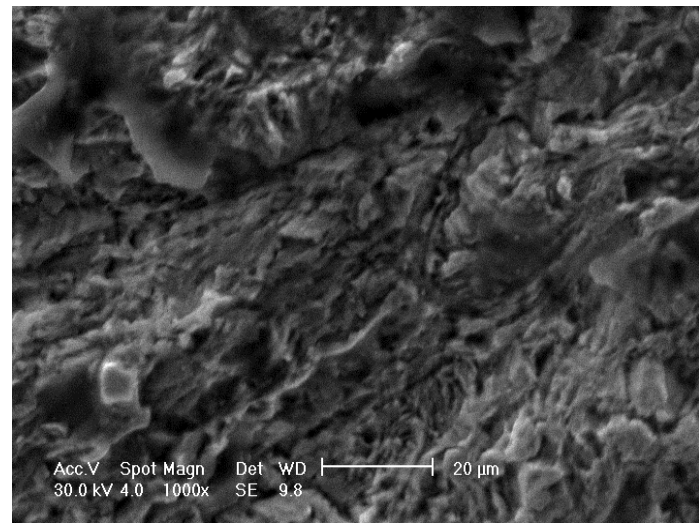

b.

Fig. 11. SEM image showing details from fracture surface with a. galling and micro-cracks and b. cleavage facets

In fig. 11.a details from a galled region are shown, the sliding direction coincides with crack growths on a NE-SV path. Branching micro-cracks can be observed parallel to this direction. In the region studied and shown in fig. 11.b same crack growth direction was observed but no galling was present.

In this case a fatigue bending failure was inferred with the origin of the crack located at implant surface.

Case study 3: tibial interlocking Kuntscher nail

The third implant studied failed in a region where section is varied, at the screw hole, as depicted in fig. 12.

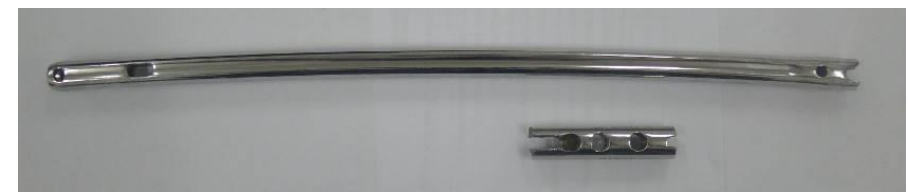

Fig. 12. Failed implant with failure located at screw hole.

By EDS the major elements present in its composition were determined and the result is shown by table 3 . 
Table 3

MAJOR ELEMENTS IN ALLOY COMPOSITION

\begin{tabular}{|l|l|l|l|l|}
\hline Element & Mo & $\mathrm{Cr}$ & $\mathrm{Ni}$ & $\mathrm{Fe}+$ others \\
\hline \%wt. & 2.05 & 13.59 & 7.39 & Bal. \\
\hline
\end{tabular}

The alloy is and AISI 316L which conforms to both ASTM F 138 and ISO 5832-1 standard specifications.

Metallographic specimens obtained from the implant were studied by light microscopy and the microstructure shown in fig. 13. a and b in transverse and longitudinal direction reveals a typical austenitic structure with fine grains and a slight preferred orientation.

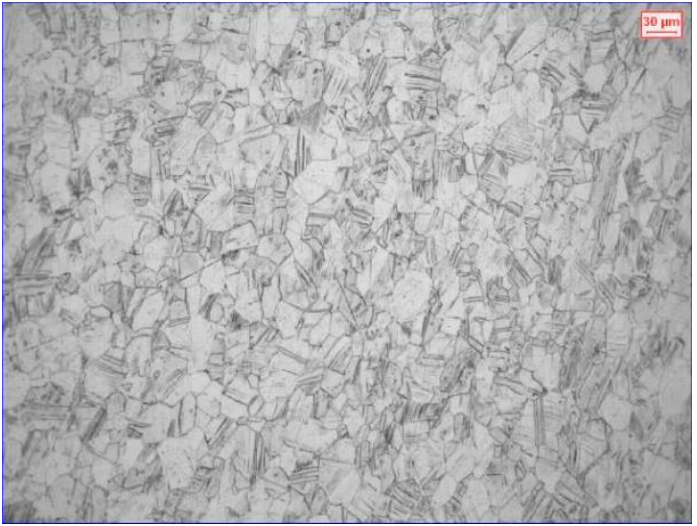

a.

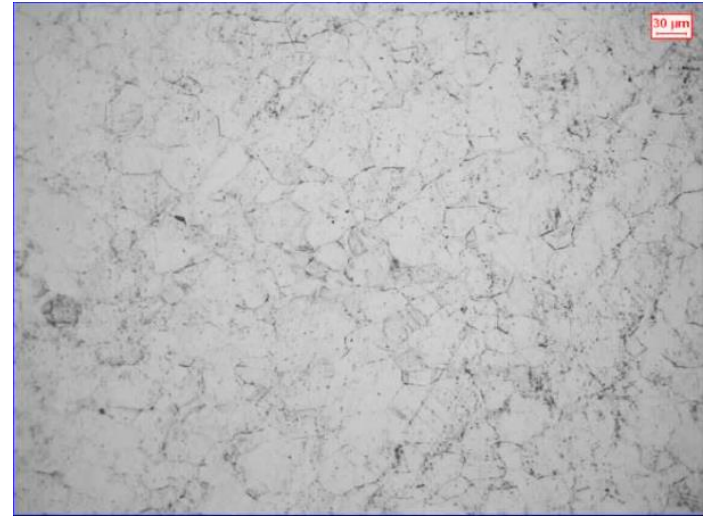

b.

Fig. 13. Optical micrograph on the implant on a. transverse and b. longitudinal direction

Observations performed using the stereo-microscope on the fractured surface revealed mixed fracture aspects, brittle and ductile, shown in fig. 14.c and predominant brittle failure in fig. 14.b. According to fracture aspects a fatigue failure can be inferred, fatigue striation and river-lines converge to crack initiation site [22] in the NE region of fig. 14.a. The loading which caused the fracture appears to be in bending.

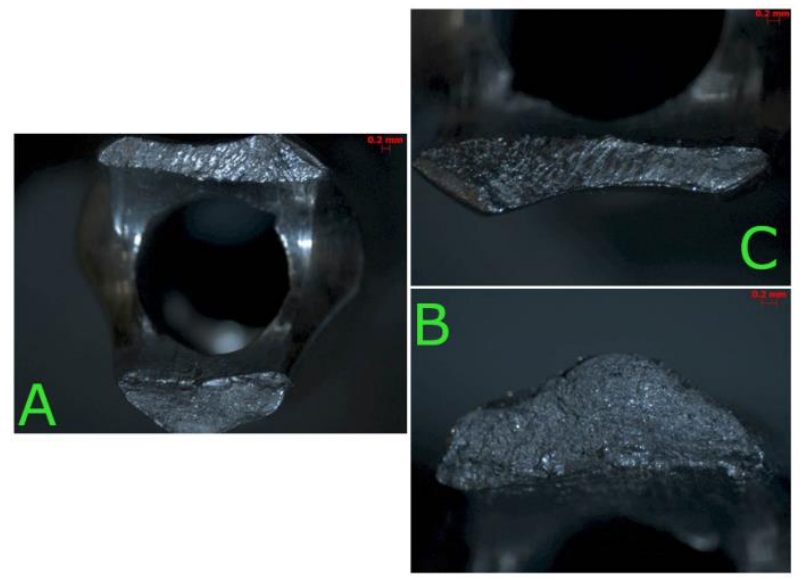

Fig. 14. Fractured implant observed using the stereomicroscope a. top view, b. and c. details on the fracture surface

Using the scanning electron microscope fracture site details were observed at higher magnifications and galling can be observed in fig 15.a and b. The arrows point towards crack initiation site. Sliding direction can be observed in fig. $15 . \mathrm{b}$ on a NE-SV direction. 


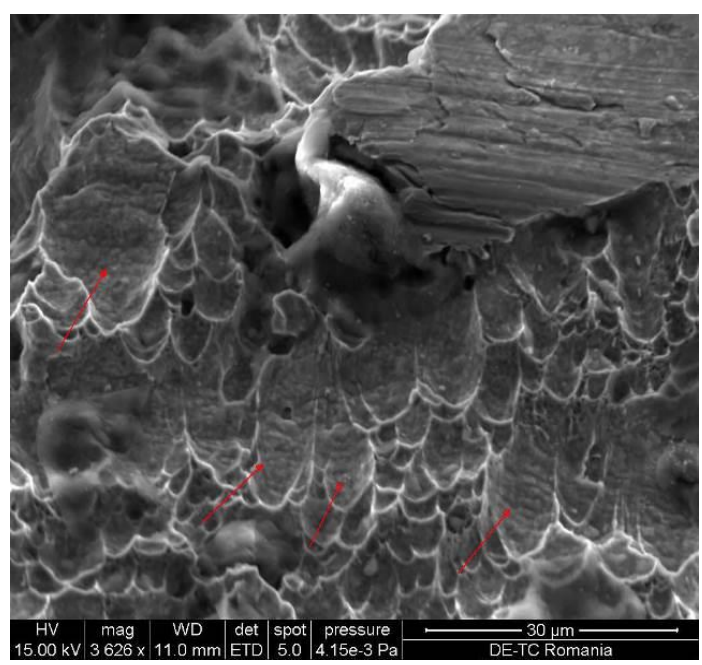

a.

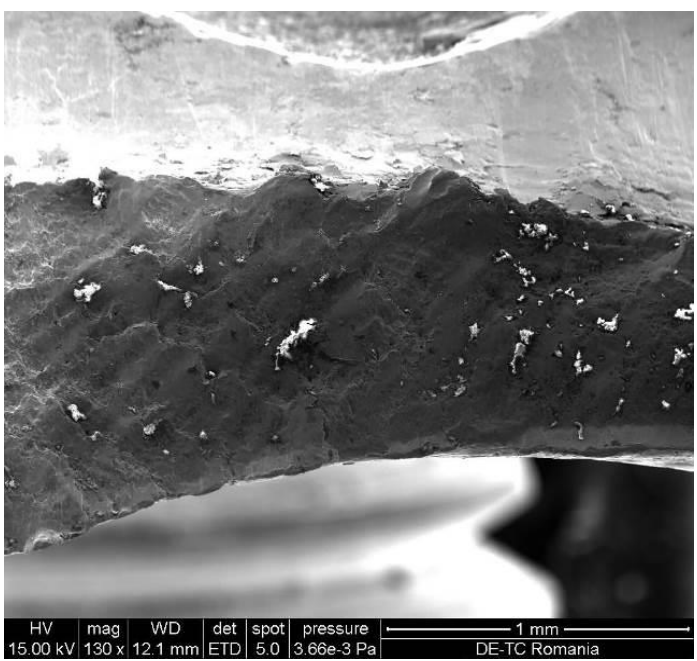

b.

Fig. 15. Fracture surface studied using SEM showing a. elongated dimples where ductile fracture occurs and $b$. galled area

The dimpled aspect presented in fig. 16 is typical for a ductile fracture and voids can be observed at the bottom. The overload causes microvoid coalescence and the elongated dimples seen in fig. 15.a suggest shearing while in fig. 16.a enhanced by artificial height coloring in fig. 16.b dimple morphology suggests a tensile loading.

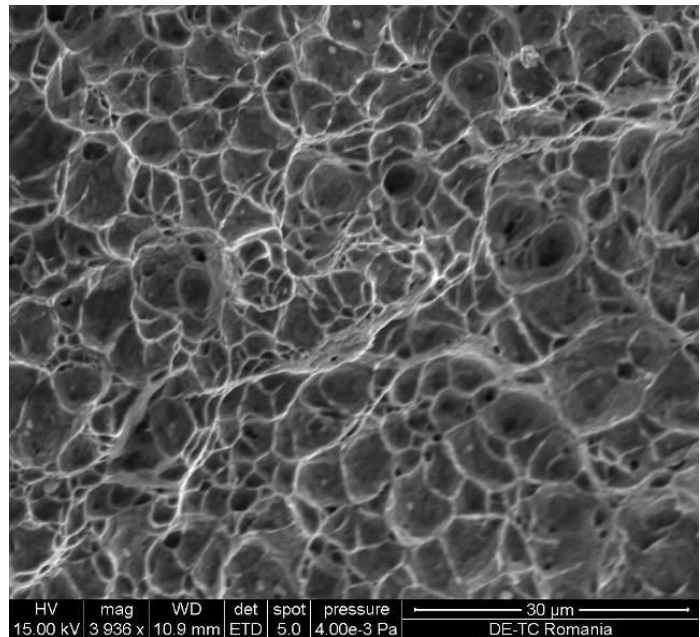

a.

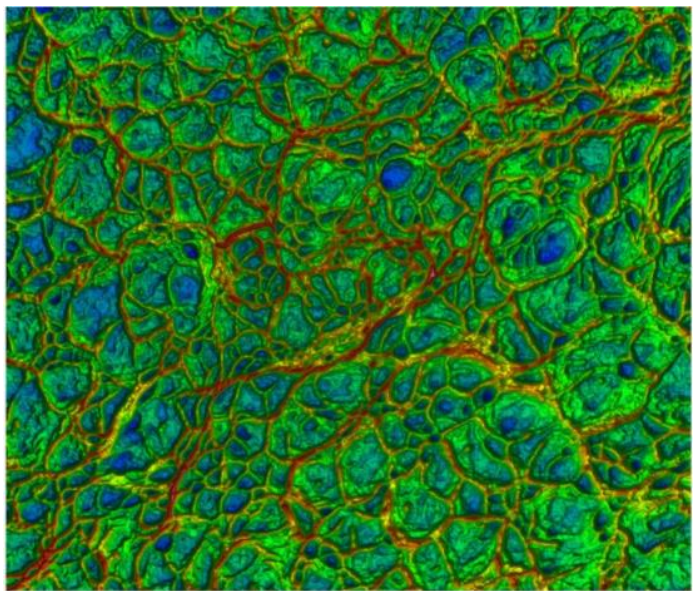

b.

Fig. 16. Scanning electron microscopy of a fracture surface showing dimples and voids in a. as acquired state and b. artificial coloring by height

The mixed fracture aspects confirm a bending fatigue failure, where a region is loaded in tension and another in compression, while the in the in-between region shear appears. The crack most likely originated at a defect near the surface, unfortunately galling covered all features that could point the exact initiation site.

\section{Part 2: Titanium alloys nails}

Along stainless steels titanium alloys are used for centro-medullar nails manufacture. The second part of the study focuses on failed implants made of titanium alloy Ti-6Al-4V.

Case study 4: Gamma3 intramedullary nailing system

The first example is a Gamma 3 centro-medullar nail which was retrieved and studied after failure. In fig. 17 the failed implant is presented. 


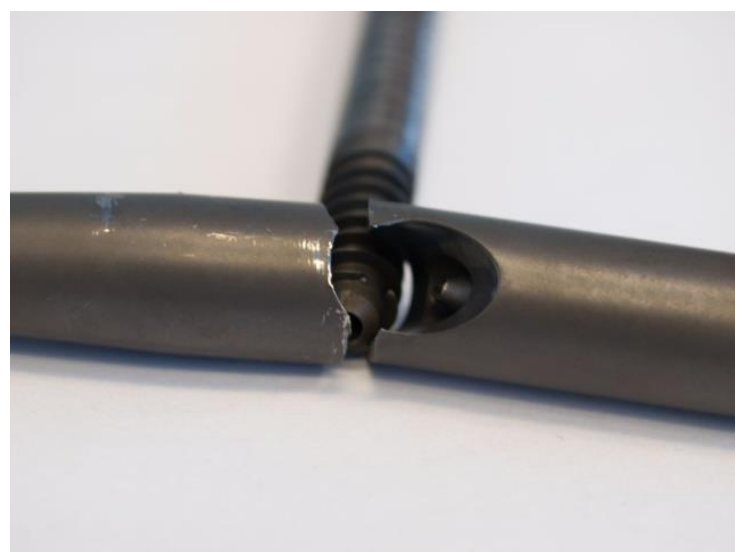

Fig. 17. Failure region of the Gamma nail

The chemical composition determined by EDS presented in table 4 suggests a titanium alloy, most likely Ti-6Al-4V.

Table 4

CHEMICAL COMPOSITION OF THE IMPLANT DETERMINED BY EDS

\begin{tabular}{|l|l|l|l|}
\hline Element & $\mathrm{Al}$ & $\mathrm{V}$ & $\mathrm{Ti}$ \\
\hline$\%$ wt. & 6.38 & 3.61 & $\mathrm{Bal}$. \\
\hline
\end{tabular}

According to ASTM F1108 and ASTM F1472 in the chemical composition of such alloys 5.5-6.75\% Al and 3.5 - 4.5\% V are required, the studied implant complies with standard specifications regarding major alloying elements concentrations.

First studies were performed by light microscopy; the metallographic sample preparation procedure was the one specific for titanium alloys [23].

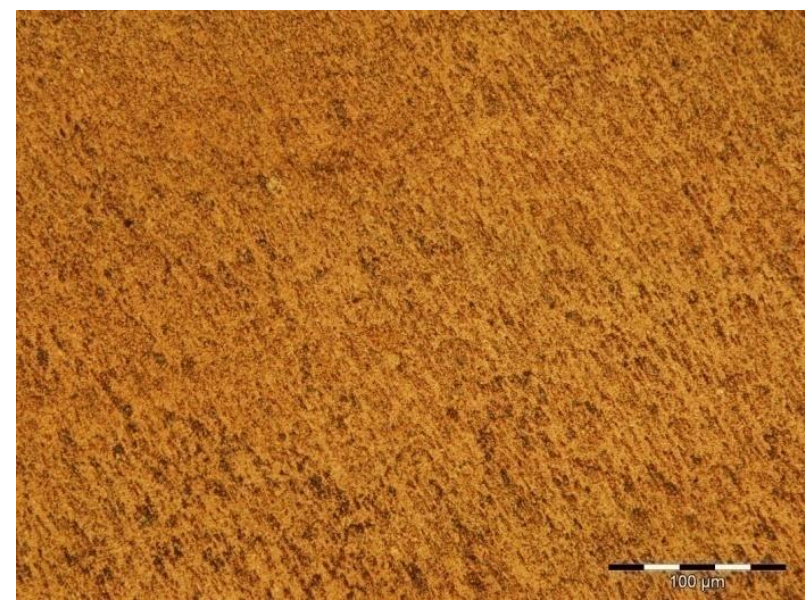

a.

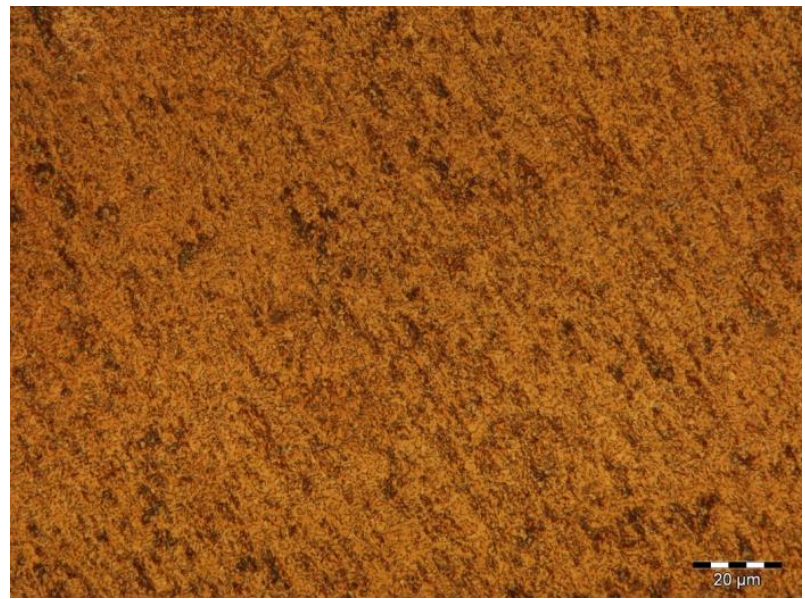

b.

Fig. 18. Optical micrographs showing Ti-6Al-4V microstructures at a. 200X and b. 500X magnification

The microstructures depicted in fig. 18 a. and b. reveal a microstructure comprised of two phases, alpha and beta, specific for this type of alloy. Phase morphology and orientation suggests a texture produced by plastic deformation of the alloy.

Fracture surface studies were firstly performed using the stereo-microscope, in fig. 19 .a to d. details of the fracture surface are shown. In fig. 19.a fracture surface is observed from a top perspective, the features observed led to a first inference that bending was the main loading type. 


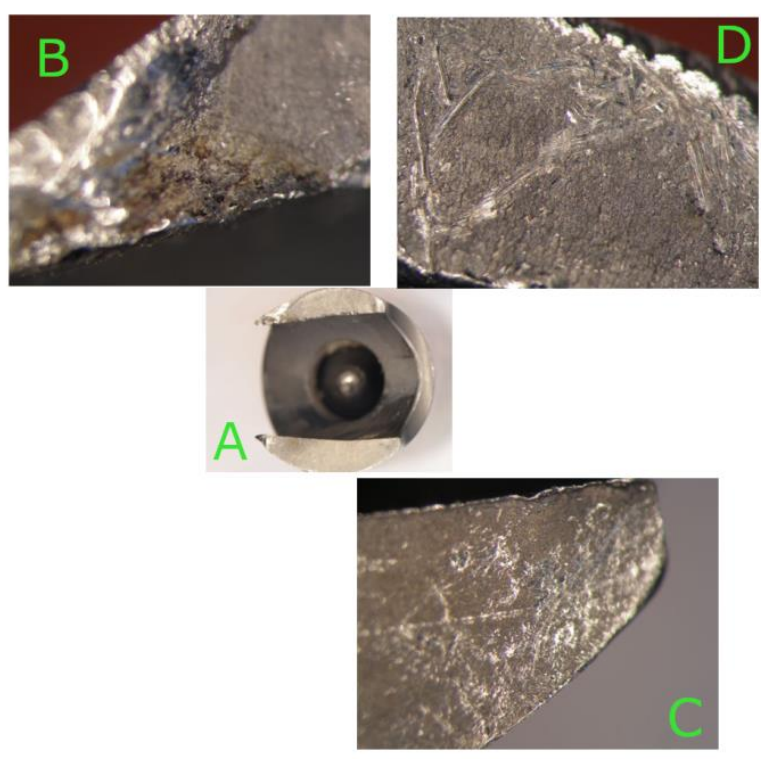

Fig. 19. Fracture surface observed using the stereomicroscope where a. shows matching fractured components and b. to d. details from the fracture surface

In fig. 19.b a corroded region was observed along brittle fracture morphology, cleavage planes and steps become obvious in fig. 19.d at higher magnifications. Deep grooves and scratches were created by the physician in his attempt to extract the implant, as observed in fig. 19.c and d.

Scanning electron microscopy studies performed on fracture surface revealed fatigue failure aspects observable in fig. 20.a and b. with a crack origin located at the surface, caused most likely by a surface defect [24].

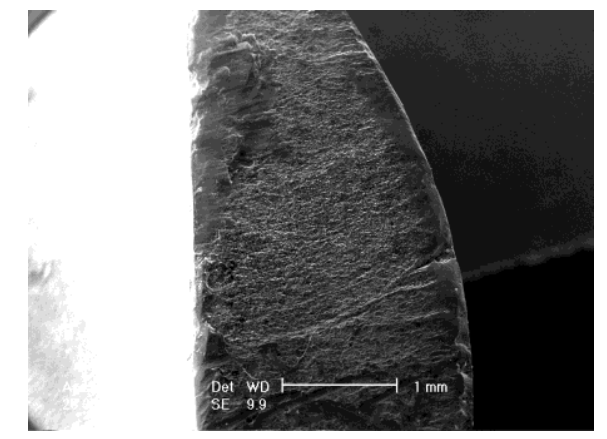

a.

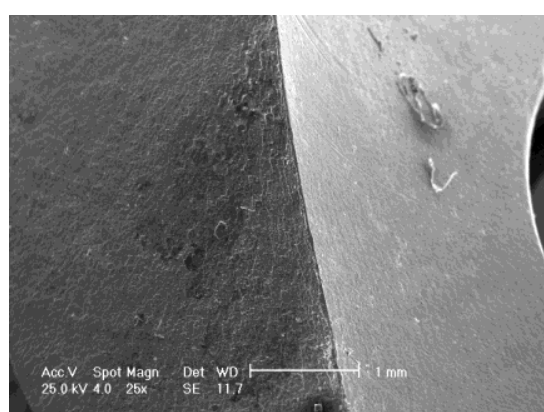

b.

Fig. 20. Fracture surface studied by scanning electron microscopy showing a. near surface crack origin and $\mathrm{b}$. river lines converging towards crack origin

Further fracture surface studies shown in fig. 21.a reveal transgranular cleavage facets with several fatigue striations observable in fig. 21. b.

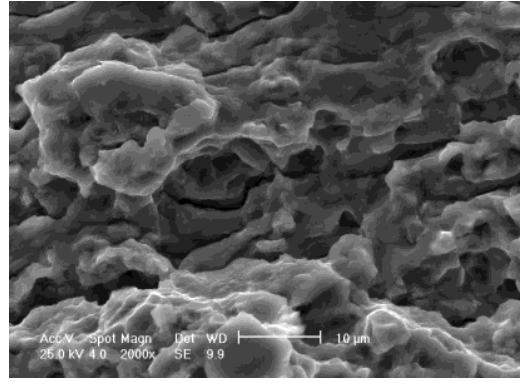

a.

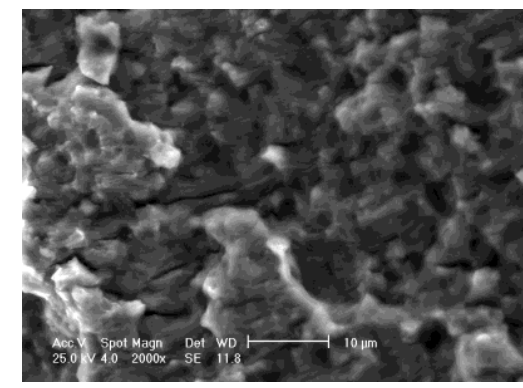

b.

Fig. 21. Scanning electron micrograph of the fractured surface showing a. transgranular cleavage facets, microcracks and $b$. fatigue striations on facets 
Fine cracks are also observable in fig. 21.a and b which are most likely to originate from alpha phase grains, given its structure and characteristics [23, 25].

The implant failed by fatigue, crack origin was found on the implant region where tensile stresses [26] are dominant.

Case study 5: tibial interlocking Kuntscher nail

The centromedullary nail shown in Fig.22 was studied given its different loading mechanism when compared with Gamma 3 nail. The failure occurred, as pointed by the arrow in fig. 22 in the distal region, at the hole.

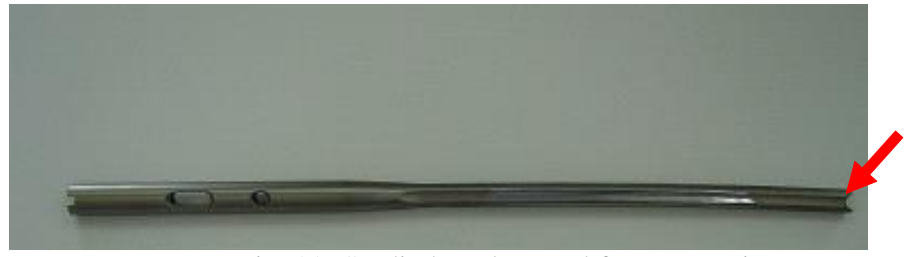

Fig. 22. Studied explant and fracture region

The chemical analysis performed by EDS showed the concentrations presented in table 5 .

Table 5

CHEMICAL COMPOSITION

\begin{tabular}{|l|c|c|c|}
\hline Element & $\mathrm{Al}$ & $\mathrm{V}$ & $\mathrm{Ti}$ \\
\hline \%wt. & 5.7 & 3.11 & Bal. \\
\hline & & & \\
\hline
\end{tabular}

According to ASTM F1108 and ASTM F1472 the Al and V contents are within standard specified limits. Studies performed by light microscopy revealed a two phase microstructure specific to a Ti-6Al-4V alloy, a mixture of alpha plus beta.

The morphology and distribution of alpha and beta tends towards a bi-modal microstructure resulting from thermomechanical processing [23], the lamellar alpha phase is deformed and oriented.

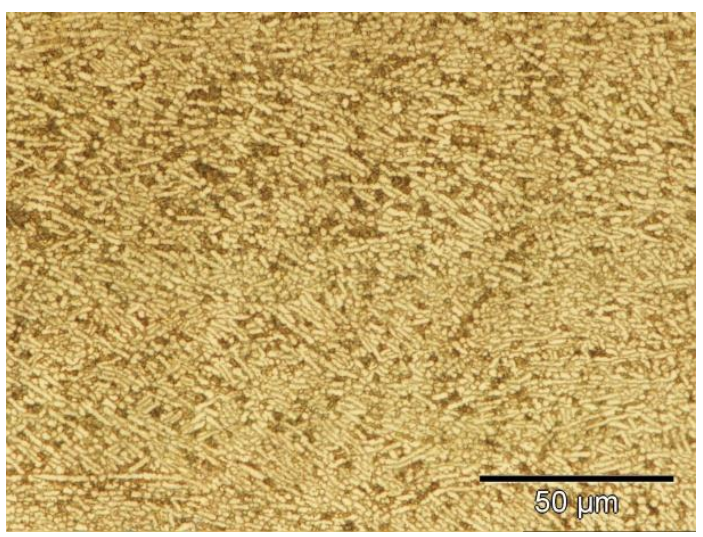

Fig. 23. Optical micrograph showing oriented alpha+beta microstructure

Studies of the fracture surface using the stereomicroscope revealed fatigue failure details similar to those presented in [27] as shown in fig. 24 a. and b. Galling appears by sliding surface contact in compression, the details are easier to identify in fig. 24.b. 


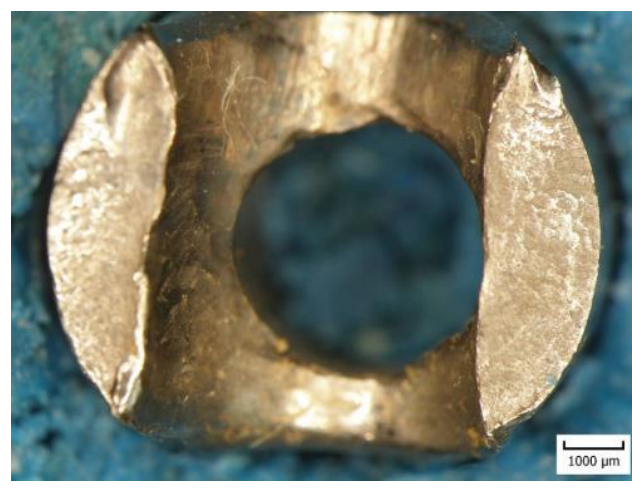

a.

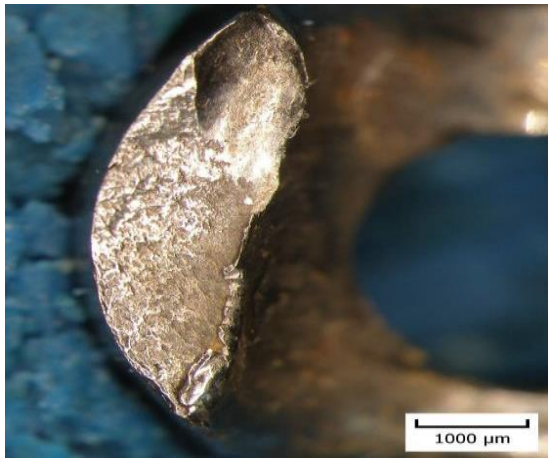

b.

Fig. 24. Fracture site study using the stereomicroscope showing a. generic fracture overview and b. detail showing galling

Scanning electron microscopy studies revealed a regions with a faceted fracture appearance, as shown in fig. 25.

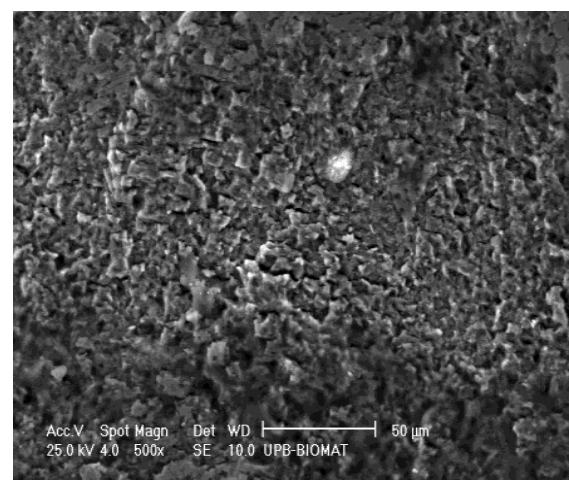

Fig. 25. Scanning electron micrograph showing cleavage facets

The failure of this implant occurred by fatigue in by bending.

Case study 6: tibial interlocking Kuntscher nail

The last failed implant from the titanium alloys series is shown in fig. 26, the failure occurred in the proximal end, opposed to the implant studied previously.

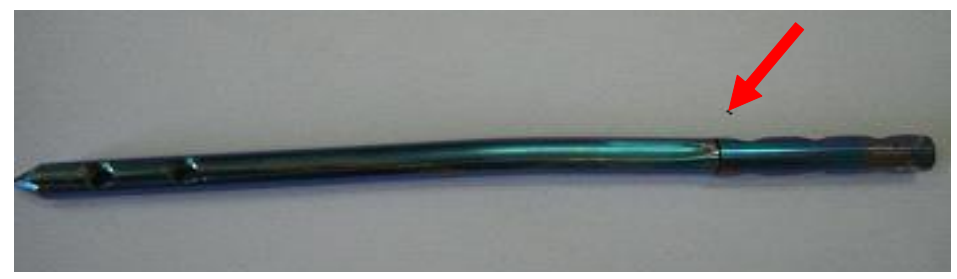

Fig. 26. Failed explant, the arrow points to fracture location

The chemical composition determined by EDS is shown in table 6 .

Table 6

CHEMICAL COMPOSITION OF THE ALLOY

\begin{tabular}{|c|c|c|c|}
\hline Element & $\mathrm{Al}$ & $\mathrm{V}$ & $\mathrm{Ti}$ \\
\hline$\%$ wt. & 5.67 & 3.59 & Bal. \\
\hline
\end{tabular}

The concentration of Al and V both comply to ASTM F1108 and ASTM F1472 specifications.

The studies using light microscopy revealed a typical microstructure formed by an alpha and beta phase mixture (Fig. 27 ), typically for Ti-6Al-4V. 


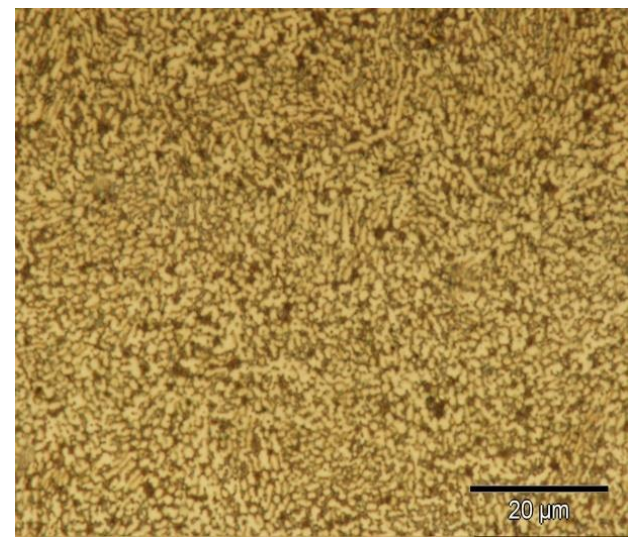

Fig. 27. Optical micrograph of the alloy showing a dual phase alpha+beta microstructure

Large inclusions and other in-homogeneities were not observed in the microstructure.

Fracture surface observed using the stereomicroscope revealed fatigue fracture details, as shown in Fig. 28. a, and mixed fracture morphologies specific to ductile and brittle failure are observed in Fig. 28.b and c.

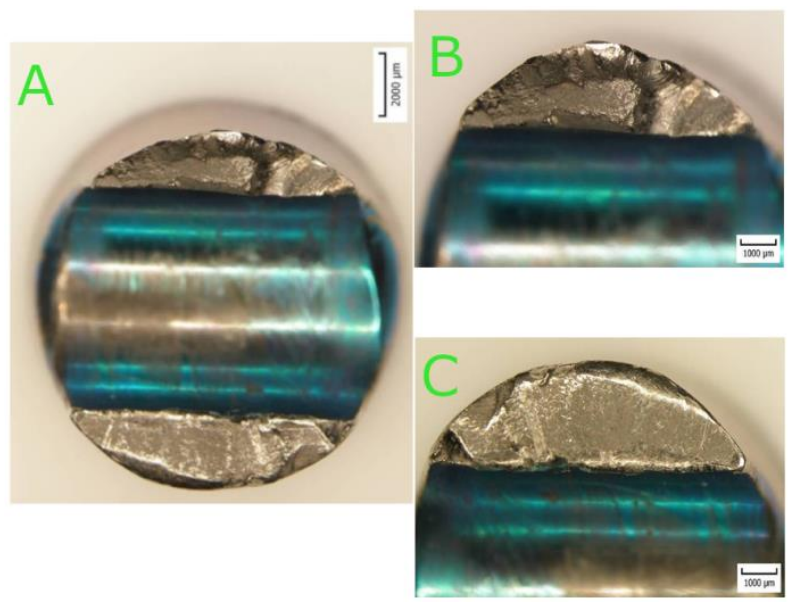

Fig. 28. Fracture surface studied using the stereomicroscope, a. general view, b. and c. details showing fatigue striations and brittle failure aspects

Fracture morphology shown in Fig. 28 suggests a bending load.

Studies by scanning electron microscopy [28-32] reveal regions galling, Fig. 29.a, fatigue striations similar to those presented in appear and river lines diverge from fracture initiation site observable in Fig. 29.c.

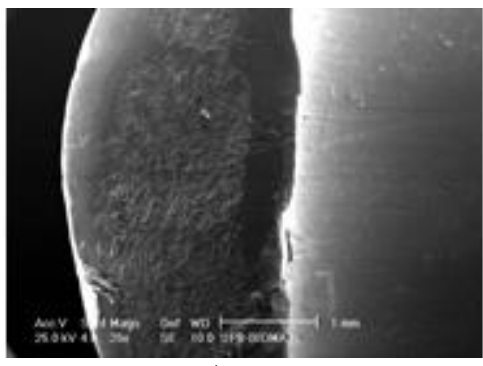

A
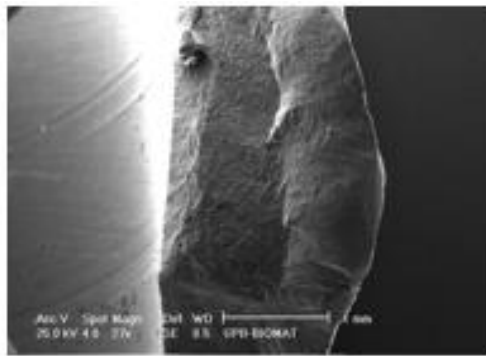

$b$

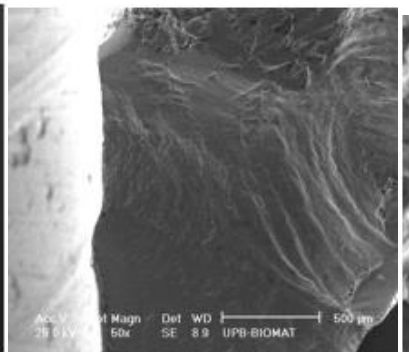

$c$

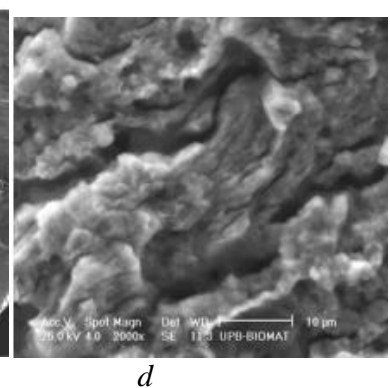

$d$

Fig. 29 Fracture surface studied by SEM details in a. showing galling, b. mixed mode of fracture, c. fatigue striations and $\mathrm{d}$. brittle fracture and micro-cracks 
Crack growth changed planes resulting in ledges as seen in Fig. 29.b, while a faceted cleavage surface appears with fine cracks oriented in the same direction in Fig. 29.d.

Fracture in this implant was caused by fatigue in bending.

Out of six mechanically heavy loaded specimens all failed by fatigue, five in bending and one in torsion loading. Whenever observable, crack origin was located near the implant surface and it was inferred that either it originates at a surface roughness feature or a dent caused by improper handling when implanted in the patient.

Another detail observed by this comparative study was the small amount of galling in the fracture surface of the titanium alloy Ti-6Al-4V, comparable with the results presented by Antoniac et al [33]. Our best guess, at current stage, was that given the lower elastic modulus of Ti-6Al-4V, 114GPa, almost half that of 316L, 210GPa, stresses are taken also by the bone. In a dissimilar materials assembly the rigid one is more stressed, thus in a titanium alloy - bone configuration the implant is less stressed than in a stainless steel - bone configuration.

Bone fracture location and implant position are important in nail failure: when distal fractures were treaded 3 out of 6 implants failed catastrophically. From a mechanical point of view the distance from bone fracture to the locking hole is very important, its increase should alter load distribution and mitigate high stresses in thin sections. Implant sizing is essential, and based upon the failure locations in this current study a section increase ore hole diameter decrease in the upper region of the implant should prevent implant failure.

\section{Conclusions}

In accordance with this and other studies performed by the authors, the implant success influence factors described previously are appreciated:

- the material and processing factors have a low incidence on implant failure. Current materials used for medical devices are regulated by restrictive standards, the inclusion content is low and the mechanical characteristics are adequate. Still these factors cannot be disregarded when failure analysis is performed.

- the design factors are important, implant sizing (nail diameter and length, hole diameters) should be appropriate for each fracture case. The need of personalized implants is obvious.

- the choice, placement and placement technique of the implant are inherently important for the success. The distance from bone fracture to locking holes and implant size are essential for load transfer. Regarding the placement technique it is the most difficult parameter to control: each clinical case has its own particularities and difficulties and the surgeon needs to adapt to onsite conditions. The scratches or indentations created on the implant surface become crack initiation sites and need to be avoided at all costs, careful screw placement and adequate handling procedures should reduce their occurrence.

- patient cooperation is needed. Sudden implant failures caused by overload were not observed in this study and had low occurrence in previous studies. Heavy implant loading speeds fatigue failure and to avoid this scenario a proper protocol associated with healing stage should be presented to the patient.

In current implant failure cases material defects and failure by overload appear seldom as failure cause while fatigue remains the main failure cause in load bearing implants.

\section{References}

1. GONZALEZ-VELAZQUEZ, J. L., Struct Integr, 2018, 3, 21-47

2. SMITH, C.S., A History of Metallography, MIT Press, 1988

3. RAICIU, A. D., POPESCU, M., MANEA, S., DIMA, S. O., Rev Chim (Bucharest), 67, 2016, p. 1936-1939.

4. POPESCU, M., PUIU, D., RAICIU, A. D., Rev Chim. (Bucharest), 69, no. 6, 2018, p. 2338-2342

5. PANTEA, M., ANTONIAC, I., et al., Mater Chem Phys, 2019, 222, 96-109

6. ALMASI, A., ANTONIAC, I., FOCSANEANU, S., et al., Rev Chim.(Bucharest), 70, no. 1, 2019, p. 336-342

7. MARINESCU, R., ANTONIAC, I., et al., Mat. Plast., 52, no.3, 2015, 340-344

8. MAVRODIN, C. I., PARIZA, G., et al., Chirurgia 108(3), 2013, 414-417

9. CHITEA, C., TOMOAIA, G., TOADER, O.D., MILEA, C., TRANTE, O., EARAR, K., SACELEANU, V., Rev Chim (Bucharest), 70, no. 4, 2019, p. $1460-1465$

10. CIRSTOIU, M., CIRSTOIU, C., et al., Mat. Plast 52, no. 2, 2015, p. 258-262

11. MARINESCU, R., ANTONIAC, I., et al., Mat. Plast., 52, no. 3, 2015, p.340-344

12. GRECU, D., ANTONIAC, I., et al., Mat. Plast. 53, no. 4, 2016, 776-780

13. RIVIS, M., PRICOP, M., TALPOS, et al., Rev Chim.(Bucharest), 69, 2018, p. 990-993

14. ANTONIAC, I., NEGRUSOIU, M., et al., Medicine 96(19), 2017

15. DI DOMIZIO, D.; TRAINI, T.; CIAVARELLI, L.; ORSINI, G.; CAPUTI, S.; SCARANO, A., J Dent Res, 80, $2001,1246-1246$.

16. WARNER, S. J., ACHOR T. S., Operative Techniques in Orthopaedics 28(3), 2018, 112-117

17. THULL, R., Eigenschaften von Metallen, fur orthopadische Implantate und deren Prufung. Orthopädie, 1979, 7:29

18. MARUYAMA, N., MORI, D., et al., Corrosion Science 53(6), 2011, 2222-2227

19. SBORDONE, L., TRAINI, T., CAPUTI, S., SCARANO, A., BORTOLAIA, C., PIATTELLI, A., J Oral Implantol, $2010,36,105-112$. 
20. SAHU, S.; YADAV, P. C.; SHEKHAR, S., Metallogr Microstruc, 2017, 6, 598-609

21. ORAVCOVA, M., PALCEK, P., CHALUPOVA, M., Modern and Safe Transport, 2017, 192, 644-648

22. GUERRA-FUENTES, L., GARCIA-SANCHEZ, E., JUAREZ-HERNANDEZ, A., HERNANDEZ-RODRIGUEZ, M. A. L., Eng Fail Anal 2015, 57, 243-247

23. GHEORGHE, D., POP, D., et al., U.P.B. Sci. Bull., Series B, 81 (1), 2019, 244-258

24. KAHLIN, M., ANSELL, H., et al., International Journal of Fatigue 101, 2017, 51-60

25. TAKAHASHI, K., SATO, E., Materials Transactions. 51(4), 2010, 694-698

26. LI, F. P., LI, J. S., HUANG, T. T., KOU, H. C., ZHOU, L., J Mech Behav Biomed 2017, 65, 814-823

27. ISMARRUBIE, Z. N., SUGANO, M., Mat Sci Eng a-Struct, 2004, 386, 222-233

28. LIMAR, L. V, Met Sci Heat Treat+ 1987, 29, 771-775

29. VILCIOIU, J. D.; ZAMFIRESCU, D. G.; CRISTESCU, I.; URSACHE, A.; POPESCU, S. A.; CREANGA, C. A.; LASCAR, I., Rom J Morphol Embryo 2016, 57, 567-572.

30. TECU, C.; ANTONIAC, I.; GOLlER, G.; YAVAS, B.; GHEORGHE, D.; ANTONIAC, A.; CIUCA, I.; SEMENESCU, A.; RAICIU, A. D.; CRISTESCU, I., Mat. Plast, 56, no. 3, 2019, p. 644-648.

31. MOLDOVAN, M.; BALAZSI, R.; SOANCA, A.; ROMAN, A.; SAROSI, C.; PRODAN, D.; VLASSA, M.; COJOCARU, I.; SACELEANU, V.; CRISTESCU, I., Materials 2019, 12.

32. PAUN, M. A.; FRUNZA, A.; STANCIULESCU, E. L.; MUNTEANU, T. C.; CRISTESCU, I.; GRAMA, S.; CHIOTOROIU, A.; ENE, A.; MIHAI, C., Ind Textila 2019, 70, 242-247.

33. ANTONIAC, I.V., STOIA D.I., GHIBAN B., TECU C., MICULESCU F., VIGARU C., SACELEANU V., Materials. 2019; 12(7):1128

Mauscript received: 20.11 .2019 